\title{
O ESTADO DO MAL-ESTAR corrupção e violência
}

\author{
Flávia SChilling \\ Socióloga. Autora de Corrupção: ilegalidade intolerável? Comissões Parlamentares de Inquérito e a luta contra a \\ corrupção no Brasil e co-autora do livro Violência urbana: dilemas e desafios.
}

Salen a la superfície, como temática fundamental de la historia, todos esos procesos obscuros que actúan en el ámbito de los grupos que se enfrentan por debajo del Estado y a través de la leyes. Es la historia oscura de las alianzas, de las rivalidades entre grupos, de los intereses escondidos o traicionados; la historia de las distracciones del derecho, de los desplazamientos de las fortunas.

Foucault, 1992:144

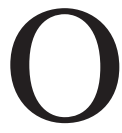
s crimes "por excelência" que despertam a atenção, a indignação e a repulsa são aqueles já conhecidos: homicídios, latrocínios e estupros. Sugerindo uma perplexa retomada de debates travados no final do século XIX, assistimos, neste final do século XX, o retorno das discussões sobre a natureza dos criminosos: monstros, endemoniados, ogros, loucos? $\mathrm{Na}$ atualidade, porém, estes crimes disputam as manchetes dos jornais e a atenção dos noticiários com outro crime pouco reconhecido como tal: a corrupção. A discussão sobre este crime, qualificado por alguns como tão antigo quanto a espécie humana, emerge com força e vitalidade surpreendentes no debate mundial e também especificamente no Brasil, a partir do final da década de 70, marcando presença no cenário político dos anos 80 e 90 . Neste período, a corrupção é colocada no debate nacional como um "problema", podendo refletir uma mudança - ora mais ora menos aguda e definida - na tolerância, aceitação ou resignação, que até então cercavam uma série de práticas assim qualificadas.

E qual é a relação entre a corrupção e a violência? Seguindo a análise de Marilena Chauí, um dos significados da violência seria "todo ato de violação da natureza de alguém ou de alguma coisa valorizada positivamente por uma sociedade" (Folha de S.Paulo, 14/03/99: 5-3). Trabalha-se com a hipótese de que a corrupção é progressivamente percebida como um "mal público", cuja noção só é passível de construção quando existe algo percebido como um "bem público", digno de defesa. Nesta lenta e conflituosa construção da noção de um "bem público", de uma nova noção de qual será o conteúdo de uma vida justa em comum, insere-se a tentativa de compreensão da corrupção como uma violência, um "mal público", um crime.

Raymundo Faoro, descrevendo as práticas do grupo criado em torno de Fernando Collor, diz: "Um bando (acepção dois) de pessoas, ancoradas em cargos públicos, se apropria da força estatal, simbolizada na portaria até a medida provisória, numa escala que vai da coerção à violência policial e policialesca. $\mathrm{O}$ bando legisla, expede ordens, dita sua vontade, vendida nos meios de comunicação de luz platinada, superior à terra e aos saberes da terra" (IstoÉ, 13/2/91:19).

A denúncia é forte e sugere, com o uso do termo "bando", em seu significado de quadrilha de malfeitores, uma situação de violência dentro de outras situações de violência: a da força estatal exercida sobre a sociedade, sem controle e limites, com o uso já comentado de medidasprovisórias (anteriormente decretos-leis), indo da coerção até a violência policial. $\mathrm{O}$ bando apropriou-se da força estatal; é a própria força estatal. É uma situação que implica a violação de algo visto como um "bem" a ser defendido: o estado de Direito, a democratização em curso. 
Porém, como é vista a relação entre corrupção e violência nos trabalhos teóricos? Nestes estudos, verifica-se a existência ou não da relação violência/corrupção internamente na relação entre corruptor e corrompido, deixando de lado o impacto da corrupção como algo que viole a natureza de algo valorizado positivamente por uma sociedade. A definição do Dicionário de Política (Bobbio, Mateucci e Pasquino, 1991:292) é clara, ao propor a corrupção como uma alternativa à violência: "a corrupção é uma forma particular de exercer influência: influência ilícita, ilegal e ilegítima (...) É uma alternativa da coerção, posta em prática quando as duas partes são bastante poderosas para tornar a coerção muito custosa, ou são incapazes de a usar."

Esta definição influenciará os estudos teóricos sobre a corrupção ao colocar, como questões centrais, a capacidade de exercer influência, quem em uma dada sociedade consegue exercê-la, a relação entre corrupção e violência, assim como uma característica importante da corrupção: a estabilidade necessária dos canais de exercício de influência ilícita.

\section{CORRUPÇÃO E VIOLÊNCIA: O CRIME E OS CRIMINOSOS}

"La corrupción es hija de las relaciones clandestinas entre el poder de la autoridad y el del dinero", diz Ocampo (1993:12), fazendo-se eco da definição proposta por Zaffaroni (1990:371) de que a corrupção "suele entenderse como la relación que se establece entre una persona con poder decisório estatal y otra que opera fuera deste poder, en virtud de lo cual se cambian ventajas, obteniendo ambas un incremento patrimonial, en función de un acto (u omisión) de la esfera de poder de la primera en beneficio de la segunda". Ambos recuperam Mills (1981:403): "quando as instituições políticas e as oportunidades econômicas estão ao mesmo tempo concentradas e ligadas, então os cargos públicos podem ser utilizados em proveito pessoal". Huntington (1975:79) segue esta linha: "a corrupção envolve a troca de ação política pela riqueza econômica." Em todas estas definições, observa-se a característica central - explícita ou não - da corrupção como exercício de influência.

A corrupção, portanto, é exercida onde existem funcionários com alto poder decisório e onde os custos de uma decisão contrária ao interesse do indivíduo são altos (perda de uma licitação, prisão, multa, etc.). A corrupção funcionaria como um "redutor de incerteza" (Mény, 1995:17) dos resultados de um determinado processo, como uma das formas de gerenciar a probabilidade.

Chama-se a atenção para um elemento que permeia todas as definições citadas e que também se encontra na definição do Dicionário de Política: existe uma relação de forças entre as partes envolvidas na corrupção, que tenderiam a se equilibrar. O processo de troca ocorreria de pleno acordo. Porém, mesmo aceitando temporariamente a diferenciação entre coerção e corrupção, sempre existe (internamente) na corrupção um fator de coerção. Tanto o funcionário com poder decisório como o detentor de poder econômico exercem coerção que subjaz à troca corrupta. São relações de poder nas quais o limite entre a corrupção - de comum acordo e na qual as duas partes se beneficiam - e a extorsão é sempre precário. Por isso, não se deve opor terminantemente corrupção e violência, mas sim entender que a corrupção, se na relação corruptor/ corrupto é uma alternativa ao uso da força, comporta uma dimensão de violência, podendo gerar e vincular-se de diferentes formas com esta.

Oliveira (1994:49-52) trata sobre esta distinção no âmbito da administração pública, diferenciando corrupção e concussão. "A concussão é uma modalidade de extorsão. Mas, como ofende um bem jurídico, que é o decoro da administração" aparece como "crime do funcionário contra a administração pública". Consiste no fato de o funcionário "exigir, para si ou para outrem, direta ou indiretamente, ainda que fora da função ou antes de assumi-la, vantagem indevida”. (...) Difere da corrupção (passiva) em que nessa a vantagem é oferecida, prometida ou dada, sem que tenha havido coação por parte do funcionário, enquanto na concussão, o funcionário exige a vantagem sob coação, (...) força ou ameaça (...) A concussão exige um abuso de autoridade do funcionário (...) a própria palavra concussão (de concussio, nis e essa do verbo concutere), indica um abalo, uma sacudidela violenta, uma agitação aterrorizante. (...) O crime de corrupção pode levar a um livre acordo entre corruptor e corrompido; no de concussão, o acordo não é livre, é o resultado de um constrangimento (...) resulta da fusão de uma corrupção com uma coação.

Essa forma de extorsão (a concussão) é especialmente grave por ser resultado de coação, de constrangimento. Klietgaard (1994:64) já dizia que a extorsão é uma forma de corrupção particularmente debilitadora, pois tende a ultrajar o cidadão-vítima.

Huntington (1975:80) discute amplamente a relação violência/corrupção em seu impacto sobre as sociedades 
em mudança. Sua hipótese é a de que "a corrupção, como a violência, ocorre quando a ausência de oportunidades de mobilidade fora da política se combina com a existência de instituições frágeis e inflexíveis, canalizando energias para o comportamento político desviante". Tanto a violência como a corrupção teriam causas e funções comuns: são encorajadas pela modernização; refletem a debilidade das instituições políticas; e são meios pelos quais os atores sociais se relacionam com o sistema político. "Tanto a corrupção quanto a violência são meios ilegítimos de se fazer demandas ao sistema, mas a corrupção é também um meio ilegítimo de satisfazer tais demandas" (Huntington, 1975:77). O autor reconhece a existência de forças sociais bem diferenciadas que utilizam estas duas capacidades de formular demandas ao sistema, ou seja, a violência e a corrupção, com a violência respondendo às demandas dos "pobres" e a corrupção àquelas dos "ricos".

Como para Huntington a preocupação central é a da ordem política nas sociedades em mudança, o autor entende a violência como a mais perigosa para a ruptura desta ordem: "o predomínio da violência apresenta uma ameaça maior ao funcionamento do sistema que o predomínio da corrupção (...) aquele que corrompe as autoridades policiais de um sistema é mais suscetível de se identificar com o sistema do que aquele que ataca as delegacias policiais do sistema" (Huntington, 1975:77). ${ }^{1}$

Vê-se, desta forma, a corrupção em seu papel conservador de distribuição desigual de poder e riqueza: "a corrupção em si pode ser um substituto da reforma e tanto a corrupção quanto a reforma podem ser substitutos da revolução. A corrupção serve para reduzir as pressões grupais para as mudanças políticas, assim como a reforma serve para atenuar as pressões de classe para as mudanças estruturais"(Huntington, 1975:77). Para o autor, se a corrupção pode acentuar as desigualdades existentes - e continuar sendo um fator de reprodução do sistema e de estabilidade política - por privilegiar aqueles que já detêm maior acesso ao poder político e, portanto, às riquezas do país, pode também ser um canal de acesso à participação política e à integração de novos grupos no sistema, assim como a corrupção decorrente da expansão da intervenção governamental pode estimular o desenvolvimento econômico.

Complementariamente, continuando com a análise do impacto do crime de corrupção sobre a sociedade, a troca que ocorre entre quem tem dinheiro e quem tem poder decisório é vista como uma das armas para a conquista ou para a manutenção do poder político. "O certo é que o dinheiro continua a ser uma arma de conquista e manutenção do poder - mais até do que aquelas três armas lembradas por Bakunine por seu largo uso nas monarquias européias: o laço corredio, o veneno e o punhal" (Geraldo Mello Mourão, 1983).

Conquista ou manutenção do poder político de um determinado status quo, atuando, portanto, como um mecanismo de reprodução de uma determinada distribuição de poder e riqueza. "A corrupção - instrumento de mudança para pessoas e grupos - tem maior probabilidade, no nível sistêmico, de dificultar, moderar, ou evitar mudanças" (Johnston, 1987:139). Como a capacidade de exercer influência ilícita não está igualmente distribuída pela sociedade, pois depende da posse de alguns recursos estratégicos (poder, dinheiro, relações sociais ou conhecimento especializado), esta será utilizada por aqueles a quem o sistema já atende bem. Desta forma, "a corrupção preserva, ou até amplia, a desigualdade já existente na sociedade" (Johnston, 1987:142-143).

Outra dimensão a ser apontada, brevemente, da relação corrupção/violência refere-se às suas múltiplas ligações com as formas atuais do crime organizado, como o tráfico de drogas, de armas, de informações que envolvem um amplo intercâmbio entre os sistemas político, financeiro e econômico, constituindo grandes ilegalidades com dimensão mundial.

Portanto, são discutidas aqui a corrupção e a violência com uma dimensão interna - própria da troca corrupta -, uma dimensão social - seu impacto na reprodução da injustiça e da desigualdade - e outra que poderia ser chamada de internacional. Constata-se, desta forma, a relação direta da corrupção com a violência: internamente, na troca "corrupta", vista como uma relação de mútuo benefício e de comum acordo entre corruptor e corrupto ou, como proposto aqui, com elementos de coerção subjacentes, posto que é uma relação de poder muitas vezes desigual, aproximando-se da extorsão; entre a relação "corrupta" e a sociedade, por tratar-se de ato de violação de algo que vai sendo valorizado positivamente pela sociedade como um "bem público", constantemente redefinido e disputado - alcance do Estado de Direito, da compreensão do que é justo ou injusto, da demanda por democratização das relações entre governantes e governados, transparência e participação nas decisões sobre o destino do patrimônio público; e uma dimensão internacional ligada ao crime organizado ou a uma nova distribuição das ilegalidades toleradas. 


\section{CRIME SEM VÍTIMA?}

Se existe o crime, se existe o criminoso, se existe a violência, quem é vítima dos crimes de corrupção? Quem é lesado? Analisando a dimensão interna da corrupção, os estudiosos dizem que: "O ato de corrupção, que pode atingir em cheio ao particular que dela é vítima, alcança no resto da sociedade um efeito por vezes diluído (...) daí que as sociedades suportem certa quantidade de corrupção sem grande prejuízo. Note-se bem: sob o aspecto ético, a corrupção é sempre grave e inaceitável, mas do ponto de vista das conseqüências práticas no todo social, ela pode dissolver-se de modo a ser absorvida sem grande dano" (Oliveira, 1994:107).

A corrupção é muito discutida como sendo um "crime sem vítima", uma vez que corruptor e corrupto geralmente beneficiam-se do ato corrupto. Onde encontrar as vítimas? Estas são encontradas quando se recupera a dimensão do impacto do crime na sociedade. Trabalha-se com a hipótese do interesse difuso, com as vítimas compondo um vasto e diluído espectro da sociedade, com a noção de vitimização coletiva. "A relação corruptor-corrupto não é diretamente lesiva ou vitimogênica em relação a terceiros. O suborno, a fraude, o peculato só atingem terceiros através de uma categoria que é o bem comum. Por isso ninguém se queixa da corrupção (...) lesado é o público, o contribuinte, o consumidor, categorias amplas, impessoalizadas, sem uma protagonização clara na vida social (...) além disso e acima de tudo, há uma tolerância geral para o que se convenciona considerar lesão contra o Estado que está em toda parte, mas não é ninguém, e em sociedades não-participativas, é sentido como inimigo comum, a ser expropriado, saqueado" (Rios, 1990:397).

Como ocorre esta progressiva percepção da corrupção como um mal que afeta toda a sociedade? Quando ela começa a provocar dano? É uma questão de quantidade?

Utilizou-se aqui a noção de mal público para caracterizar a corrupção, seguindo a definição de Santos (1993:51), quando este autor propõe que o mal público origina-se de uma interação social conflitiva, caracterizando-se por ser de consumo compulsório, podendo ser discreto (política salarial setorial depressiva) ou contínuo (poluição), categórico (atingindo uma coletividade determinada) ou inclusivo (como a inflação ou a corrupção). Esta percepção da corrupção enquanto vitimização coletiva, um mal público, implica, portanto, o progressivo traçado dos limites entre as esferas pública e privada, entre os limites do uso do que é comum - público -, superando a idéia de que "o súdito, a sociedade, se compreende no âmbito de um aparelhamento a explorar, a manipular, a tosquiar nos casos extremos" (Faoro, 1987:733).

Porém, a luta contra a corrupção geralmente não mobiliza: qual é a explicação para este fato, uma vez que o lesado somos todos nós, por se tratar, por exemplo, do uso do "meu dinheiro, seu dinheiro, nosso dinheiro"? Onde estamos, onde está o povo quando se refere ao crime de corrupção? O "povo" é descrito como desencantado, perplexo, atônito, confuso, cansado, cordato, excitado, desconfiado, relutante, oscilando. "O que vai de fato, pelo coração e pela mente do povo? Esta é a pergunta essencial, difícil de responder" (Fernandes, 1989:31).

Uma das vertentes explicativas para a não participação é a do descrédito profundo nos políticos e nas instituições políticas, descrédito aparentemente inabalável. O espaço da política seria, por definição, um espaço sujo e que suja, com um potencial diabólico de corrupção. O espaço da política seria comparável ao 'mar de lama' e geraria uma rejeição global aos políticos, uma recusa a tudo o que se relaciona com a política. Neste espaço, o povo não teria lugar: a política é a política dos outros. É um espaço reservado para os profissionais da política e estes tradicionalmente decepcionam, num processo visto por alguns como natural: "normalmente, quando as coisas vão mal, os cidadãos tendem a responsabilizar os políticos. É um processo natural" (Orestes Quercia, 1992:5-7).

Se a figura do político tradicionalmente decepciona, a decepção é proporcional à esperança por ele gerada. Santos (1993:105), analisando a cultura cívica brasileira, entendida como o conjunto de expectativas que os indivíduos têm em relação ao governo, a seus concidadãos e a si próprios, verifica a fraca credibilidade institucional que se traduz na baixa participação política, sindical e associativa.. "À óbvia e escandalosa ausência de capacidade participativa (ou motivação) e à reduzida taxa de demandas, some-se absoluto descrédito na eficácia do Estado" (Santos, 1993:99). Esta equação não é formada por termos independentes e sim interdependentes. A ausência de motivação para a participação explica-se quando se pensa o Brasil poliárquico e o Brasil "hobbesiano" analisado por Santos, constituindo-se mutuamente, ou, como sugere Martins (1994:13), com o atraso como um instrumento de poder.

Outra vertente explicativa considera que a ausência de exemplos positivos provenientes das autoridades políticas contaminaria o povo, que consideraria normais os comportamentos de setores da elite brasileira. 
A relutância do "povo" em participar da luta contra a corrupção encontraria sua explicação na recuperação da história do Brasil, com a visão destas práticas como prerrogativas das elites e, portanto, dos políticos, com a consequiência de não serem vistas como práticas ilegais. $\mathrm{O}$ silêncio do povo é interpretado como reflexo da histórica acomodação geral no "jeitinho", na risonha complacência com comportamentos transgressores. A onda de denúncias não mobiliza, os escândalos não impressionam, fazem parte da normalidade da situação brasileira. Este termo "corrupção", tão plástico e generoso e contendo uma multiplicidade de práticas, estaria sendo preenchido por um conteúdo não reconhecido como ilegal ou imoral.

Além disso, a não participação popular na luta contra a corrupção deve-se não apenas ao fato de esta apoiar-se em mecanismos tradicionais de troca de favor, de clientelismo e de privilégios de elites, mas também em função da fraca significação do que é "coisa pública". Discutindo sobre a clássica dicotomia público/privado, como termos que se condicionam e delimitam reciprocamente, Bobbio (1992:14-15) aponta que esta distinção "reflete a situação de um grupo social no qual já ocorreu a diferenciação entre aquilo que pertence ao grupo enquanto tal, à coletividade, e aquilo que pertence aos membros singulares. Não se trata, desta forma, de uma delimitação formal - pela lei - de esferas, mas sim do que cada coletividade compreende como pertencendo legitimamente a cada esfera.

A ausência do "povo" nestes episódios, portanto, encontra uma explicação na combinação de vários fatores, que, inicialmente, não são considerados relativos à população, tratando-se de uma briga entre ricos e poderosos, sendo estes, surpreendentemente, denunciados por práticas até então vistas como normais. Verifica-se, também, que estamos em presença de um movimento de construção de um campo litigioso que coloca em questão a delimitação entre o público e o privado, construindo-se no decorrer do processo a verificação de competências, do que é comum, do que é de cada uma das partes e quais são os limites a serem construídos. Além disso, não basta que uma série de comportamentos sejam percebidos como ilegais, ilegítimos ou injustos. É preciso que se tenha confiança de que a ação gere algum resultado, de que o apelo seja escutado e acolhido e que se possa contar com uma atenção dos órgãos encarregados de investigar, julgar e punir. Não basta o reconhecimento de um fato como injusto: é preciso acreditar na possibilidade de mudança.

\section{O ESTADO DO MAL-ESTAR: CPIs E JUDICIÁRIO}

O que aconteceu para que práticas tidas como "normais" começassem a ser progressivamente vistas como ilegais ou ilegítimas? Pode-se considerar que se trata de uma "criticabilidade" profunda do sistema político brasileiro, com o questionamento de práticas tidas até então como "normais", que, segundo Faoro (1987:744), "no exagero das cores", produzem uma conseqüência: "o povo quer a proteção do Estado, parasitando-o, enquanto o Estado mantém a menoridade popular, sobre ela imperando (...) a dualidade oscila entre a decepção e o engodo."

O marco desta discussão pode situar-se na perspectiva foucaultiana de "crise das ilegalidades toleradas". A crise de uma determinada "economia das ilegalidades" ligar-se-ia a transformações mais gerais da sociedade, tanto de ordem econômica quanto cultural. A idéia de "crise" introduz na discussão o caráter de permanente tensão entre esse conjunto de normatizações ou formas de gestão as ilegalidades toleradas -, o seu caráter de constante negociação tanto com as leis ou normas "editadas" como entre si, revelando o estado das lutas sociais. Aponta-se a relação para a redistribuição das ilegalidades - a crise das ilegalidades toleradas -, com os movimentos mais gerais da sociedade se entrecruzando com os conflitos sociais, participando da luta contra os regimes políticos, respondendo aos efeitos das crises econômicas (Foucault, 1984: 240).

Desta forma, têm-se, por um lado, as ilegalidades em seu papel de manutenção e conservação de uma dada distribuição desigual de riqueza e poder e, por outro, no momento da "crise das ilegalidades", a sua utilização como arma política, tanto sendo incorporadas como incorporando movimentos políticos e sociais mais amplos. Momento de questionamento, portanto, dos limites ou fronteiras do tolerado e do intolerável, do que será considerado legítimo e do que será considerado ilegítimo, do cruzamento do legal e do legítimo, do que será, doravante, considerado crime.

Seria possível supor, portanto, na atualidade, a presença de um campo de litigiosidade, estruturando-se através da crítica e da denúncia sobre corrupção na administração e nos diversos poderes públicos, de tentativa de criminalização de práticas que, mesmo definidas como crimes no Código Penal, eram até então toleradas, ou incorporando novas práticas, não previstas no Código Penal, como criminosas. 
Segundo Sousa Santos, os litígios são construções sociais que emergem e se transformam segundo dinâmicas sociologicamente identificáveis, com os diferentes grupos sociais apresentando percepções diferentes das situações de litígio e níveis de tolerância diferentes frente a estes. Para que um comportamento ou conjunto de ações seja percebido como litigioso, não é suficiente o reconhecimento de seu caráter lesivo, provocando dano ou injustiça: "é necessário que o lesado ache que o dano é de algum modo remediável, reclame contra a pessoa ou entidade responsável pelo dano de que é vítima e saiba fazê-lo de modo inteligível e credível" (Sousa Santos, 1996:50-51).

Se o ponto de partida é o reconhecimento do dano ou da injustiça, da determinação de responsabilidades, é também necessária a constatação de que é possível atuar, de que existem possibilidades e canais efetivos de reparação. É este um dos aspectos centrais desse artigo: se a corrupção não é uma série de práticas inevitáveis, se tem responsáveis e implica um dano, existe a percepção de que é possível atuar, de que existem canais para a reparação do dano e da injustiça?

\section{Comissões Parlamentares de Inquérito}

As CPIs adquirem uma especial importância a partir da década de 80, ocupando manchetes de jornais e disputando audiência com as novelas. Estas Comissões constituem cenário privilegiado para estudar como são recolhidas e elaboradas as denúncias sobre corrupção, permitindo compreender a importância do que está em jogo quando se fala em corrupção e por que se fala de corrupção: arma, estratégia, foco para introduzir o debate sobre limites no uso dos recursos públicos, sobre a distribuição dos recursos públicos, sobre a legitimidade de certas práticas de governo e de certos privilégios econômicos e sobre a configuração dos poderes no Brasil.

Instituto profundamente desprestigiado, foi crescendo em importância principalmente a partir da Constituição de 88. Oliveira e Passos (1990:43), em estudo sobre as CPIs do Senado, cujo objetivo é a avaliação dos aspectos metodológicos de seu funcionamento do ponto de vista da eficácia e da eficiência, afirmam que, mesmo que as CPIs sejam reconhecidas e definidas como um tema de paixão política "tratado ora com arroubo, ora com descaso, vê-se prisioneiro de interesses passageiros (...) muito pouco estudado com auxílio de métodos científicos”. Os autores apontam para a existência de uma "irônica cor- respondência entre a proclamada ineficiência das CPIs e a improdutividade intelectual", pois "pode-se afirmar que as CPIs da Câmara dos Deputados não são objeto de estudo científico há mais de quarenta anos e que as do Senado Federal nunca o foram em toda a existência da instituição" (Oliveira e Passos, 1990:47). Tanto a improdutividade intelectual quanto a ineficiência do instituto podem ser pensadas no contexto maior do desprestígio do Legislativo e na descrença em sua possibilidade de atuação independente frente ao Executivo.

Tratando da gênese da Lei oํ 1.579, de 1952, que regula a existência e funcionamento das CPIs, Oliveira e Passos transcrevem parecer de Aloysio de Carvalho, com a seguinte conclusão: "é indisfarçável a importância do papel que as comissões parlamentares de inquérito desempenham (...) dentro, especialmente, do sistema presidencial, com o resguardarem, enquanto possível, o princípio de equilíbrio dos poderes, invalidando, quiçá, o predomínio total do Executivo. O presidencialismo brasileiro, que dessa maléfica hipertrofia vem sofrendo, mais do que qualquer país do mesmo tipo de governo, poderá encontrar não o remédio - que remédio não há -, mas ao menos o paliativo, na prática inteligente e cautelosa dos inquéritos parlamentares" (Carvalho apud Oliveira e Passos, 1990:21).

Independentemente do pessimismo do legislador sobre a ausência de remédios para os males do presidencialismo brasileiro com seu enorme predomínio sobre os demais poderes, observa-se, claramente apontada por ele, a função política das comissões. Esta análise serve de guia para a leitura dos resultados da pesquisa de Oliveira, que verificou a eficácia e a eficiência das CPIs do Senado de 1946 até 1989, cobrindo o período das Cartas de 1946 a 1988.

As hipóteses que a pesquisa sobre a atuação das CPIs do Senado tentará comprovar ou refutar são as seguintes: o regime presidencialista favoreceria a instalação e o funcionamento das CPIs; estas funcionariam como uma prerrogativa das minorias, pois um terço dos deputados ou senadores podem criá-las, verificando-se, porém, se o alcance desse poder é somente o de criá-las ou se é possível conduzir as investigações até a aprovação das conclusões; o baixo rendimento das CPIs dever-se-ia à inflação das Comissões, à falta de persistência ou método, a maciças maiorias governamentais nas câmaras e à longa duração dos trabalhos.

Foram nos governos de João Figueiredo e de José Sarney que ocorreu o maior número de Comissões, sendo que no último verificou-se a instalação de 17 delas (Oliveira 
e Passos,1990:61-74). O maior intervalo foi registrado na administração Juscelino Kubistchek, com a instalação da primeira CPI no 35 mês de seu governo, e o menor ocorreu no governo de João Figueiredo (no $2^{\circ}$ mês de governo). Considerando macroperíodos de governo, o intervalo entre CPIs instaladas foi de 12,8 meses no período "democrático", aumentando para 14,8 no "militar" e diminuindo para 5,3 no da "Nova República". ${ }^{2}$

A qualidade deste incremento investigativo por parte do Poder Legislativo pode ser melhor percebida ao relacioná-la com os objetivos das CPIs. A classificação das CPIs por seus objetivos explícitos não é tarefa fácil, pois seus títulos são extremamente gerais e vagos. Estas são classificadas como "sentenciadoras" - apuração de irregularidades e responsabilidades -, "avaliadoras" - estudos, análises e avaliações temáticas - e "híbridas ou mistas" (Oliveira e Passos, 1990:55). Até 1985, das 11 CPIs arroladas, oito enquadrar-se-iam como "avaliadoras" e três como explicitamente "sentenciadoras". Mesmo contando com um intervalo sem CPIs (de 1985 a 1987), no período 1987-89, das 12 CPIs arroladas, oito seriam consideradas "sentenciadoras", contra quatro "avaliadoras", numa clara inversão das características das CPIs instaladas.

Discutindo as prerrogativas das minorias de criarem CPIs, com estas cumprindo o papel fiscalizador das ações da maioria governamental, a pesquisa conclui que, se os oposicionistas criaram $20 \mathrm{CPIs}$, presidiram 18 e relataram apenas quatro, os governistas criaram 12, presidiram 14 e relataram 26: "a oposição perde o impacto de sua ação ao longo do transcurso de realização da CPIs e a situação percorre o caminho inverso (...) as trocas de parlamentares ao longo dos trabalhos foram sempre feitas em prol dos governistas e em detrimento dos oposicionistas (...) Para CPI do tipo 'sentenciadora', predomina a homogeneidade política do par presidente-relator e para as do tipo 'avaliadora' e 'híbrida', o par dominante é presidente oposicionista-relator governista. No conjunto, a relatoria quase sempre fica em mãos de parlamentares de partidos governistas" (Oliveira e Passos, 1990:68-85). Observa-se que este perfil modifica-se nos últimos anos, com oposicionistas ocupando a relatoria de CPIs importantes.

A pesquisa conclui que não houve "inflação" de comissões de inquérito no Senado que justificasse sua ineficiência. Esta ineficiência reflete-se no fato de que apenas 19 Comissões, no total de 37, chegaram ao Relatório final, e, destas, somente oito apresentaram projeto de resolução relativamente às conclusões, sendo que seis foram aprovados (Oliveira e Passos, 1990-78-85). O desem- penho ineficiente das CPIs estaria vinculado, principalmente, ao tipo de relação política estabelecida com o Executivo. Os autores descartam a relação entre este desempenho e a criação de CPIs "pró-prestígio" que se ateriam a investigações circunstanciais. "A motivação (do baixo desempenho) pode estar mesmo no jogo político de apoio ao Executivo, pela criação de 'CPI fantasmas', o que leva ao estiolamento do instituto" (Oliveira e Passos, 1990:87).

Atualmente, devido à visibilidade de algumas CPIs "completas" e que conseguiram levar a cabo com êxito investigações e oferecer recomendações, estas Comissões são novamente consideradas instrumento poderoso nas disputas por poder e prestígio político. De qualquer forma, vale a observação da pesquisa de Oliveira e Passos (1990:69) de que o êxito das Comissões é indissociável de sua natureza política, sendo que "o êxito investigatório de CPIs que se deixam perceber como instrumento de fiscalização do Legislativo como um todo poderá estar indicando falta de apoio parlamentar ao Governo", ou, de forma mais ampla, de um momento de especial confronto entre os Poderes dentro de uma dada conjuntura política.

$\mathrm{Na}$ análise dos relatórios das CPIs, algumas características merecem ser destacadas: a marcante presença da imprensa detonando os processos investigativos das CPIs e provocando sua continuidade; e o papel do "acaso", dos "imprevistos", do "destino", dos depoimentos que trazem revelações inesperadas. A frase tão conhecida: "sabe-se como começa uma CPI, nunca se sabe como termina" relaciona-se com a idéia de estas Comissões serem como "bolas de neve". Se são geralmente controláveis, as CPIs podem deixar de sê-lo, com todas as conseqüências daí decorrentes. Se são cercadas pelo descrédito, se muitas vezes os próprios parlamentares não acreditam nelas, outros podem acreditar e revelar fatos que obriguem o prosseguimento das investigações.

Isto acarreta um problema central das CPIs que tratam de casos de corrupção, traduzido na delimitação do significado de "fato determinado" 3 a ser investigado e que marca o seu limite legal de atuação. Como observa Bezerra (1993), a delimitação de um caso de corrupção é sempre problemática.Verifica-se, com a discussão do "fato determinado", a tentativa de colocação de limites para o "caso", de demarcação de fronteiras que são sempre violadas, pois uma denúncia leva a outra, a investigação de uma irregularidade leva à descoberta de outras.

No Relatório da CPI que investigou as atividades de PC Farias, em 1992, encontram-se oito páginas de dis- 
cussão sobre a compreensão de "fato determinado", recuperando-a na história constitucional e na história das Comissões do Congresso, mostrando um grande esforço de interpretação, do qual depende a existência legal desta CPI. A discussão sobre o significado de "fato determinado" serve como confirmação para o caráter artificial da delimitação de um caso: a tentativa de reconhecimento de algo como fechado, com fronteiras marcadas, que se revela aberto, amplo, ramificado, generoso. Tenta-se, na delimitação do "fato determinado" - conjunto de práticas ligadas a determinado modo de governar e fazer política -, que se mantenha no plano da moralidade pessoal de determinados governantes, como algo excepcional que degrada ou deteriora instituições.

Poder desprestigiado, neutralizado em sua função fiscalizadora, contando a partir das disposições constitucionais de 1988 com o poder das CPIs, o Legislativo, através do confronto com o Poder Executivo e demais poderes, tentará recuperar essa função, assumindo algum protagonismo na demanda pela defesa do bem público, postulando algum grau de independência frente ao Executivo.

\section{O Judiciário}

Porém, a CPI pode investigar, mas não punir: falta a Justiça em cena. Esta ausência configuraria um clima de cinismo, desalento: fala-se em país da impunidade. Se as práticas agrupadas sob o nome de corrupção começam a ser percebidas como lesivas, como um "mal" que tem responsáveis, não existe ainda o reconhecimento da existência de meios efetivos para sua investigação e, muito menos, para sua punição.

"A tibieza dos tribunais no domínio da justiça distributiva e dos direitos sociais e econômicos se prolonga também no domínio do combate da corrupção, o qual (...) tem vindo a constituir, juntamente com a tutela dos interesses difusos e do meio ambiente, uma área privilegiada de protagonismo político e visibilidade social dos tribunais nos países centrais" (Sousa Santos, 1996:45).

Existe um reconhecimento do papel da Justiça enquanto instrumento para o controle diferencial das ilegalidades, com a existência de punição para certos crimes e de impunidade para outros, da diferença de tratamento dado ao furto contra a propriedade particular e ao furto contra a propriedade pública (corrupção) e do exercício de influência ilícita. Existe um desgaste que afeta profundamente a credibilidade simbólica da tutela judicial. A fraca presença do Judiciário na resolução dos conflitos, especialmente nos que envolvem questões políticas, encontraria, segundo Sousa Santos (1996:58) uma explicação mais geral: "nos países periféricos e semiperiféricos, o garantismo esteve, por assim dizer, em crise desde o início. Nesse sentido, as responsabilidades políticas do Judiciário são menores apenas porque é menor a legitimidade do sistema político no seu conjunto. A relativa irrelevância social dos tribunais é assim o outro lado da distância do sistema político em relação aos cidadãos."

Se o contexto descrito é de inquietação, de descrédito em relação às funções dos tribunais, ou de percepção dessas funções como gerindo dois tipos de ilegalismos que respondem a critérios de classe, com a delinqüência própria à riqueza tolerada pelas leis e certa da indulgência dos tribunais quando cai em seus domínios (Foucault, 1984:82), existe a percepção, por parte dos operadores do Direito, do custo simbólico dessa situação e a necessidade de modificá-la.

Observa-se, desta forma, uma série de convocações em curso. Uma destas convocações é do Legislativo, através do instituto das CPIs, com seu objetivo explícito de recuperação de prestígio, de afirmação de capacidade do exercício da fiscalização, da representação e da legislação, recuperando espaços de independência frente ao Executivo. Outra é do Judiciário e do Ministério Público, com uma nova visão do Direito, articulada aos movimentos sociais. Vale ressaltar o protagonismo do Ministério Público a partir de seu novo desenho constitucional na defesa do "bem público", como uma das novidades do cenário político, "desacomodando" antigas e arraigadas visões e práticas de gestão pública. Um Ministério Público republicano e democrático entra em cena marcando a existência da possibilidade da construção de novos limites entre o público e o privado.

Este é, em breves traços, o "estado do mal-estar": corrupção e violência disputando espaços no cenário da atualidade, exigindo a atenção de várias instituições, provocando polêmicas, colocando em questão antigas práticas - ilegalidades toleradas -, redefinindo os novos limites do público e do privado e da mentira e do segredo na política, na gestão democrática da coisa pública.

\footnotetext{
NOTAS

E-mail da autora: oak1@ig.com.br

1. Chama-se a atenção para o fato de que a observação de Huntington sobre o papel "corrosivo" da violência deve ser contextualizada: neste trecho, trata-se da violência revolucionária, que pode significar uma ameaça ao sistema. Ao contrário, a violência da criminalidade já foi extensamente analisada como "funcio-
} 
nal" ao sistema, por justificar o policiamento do cotidiano, a vigilância dos cidadãos, o florescimento de uma série de atividades legais ligadas à segurança, envolvendo a criação de grandes fortunas, a construção da figura do trabalhador por contraposição à do delinqüente.

2. Na pesquisa, foram assim definidos os macroperíodos de governo: 1은 macroperíodo: de 1947 a 1968; 2 macroperíodo: de 1969 a 1978; e 3o macroperíodo: de 1979 a 1989 (Oliveira e Passos, 1990:74).

3. CF 1988, Art. 58, 3 "As comissões parlamentares de inquérito, que terão poderes de investigação próprios das autoridades judiciais, além de outros previstos nos regimentos das respectivas Casas, serão criadas pela Câmara dos Deputados e pelo Senado Federal, em conjunto ou separadamente, mediante requerimento de um terço de seus membros, para a apuração de fato determinado e por prazo certo, sendo suas conclusões, se for o caso, encaminhadas ao Ministério Público, para que promova a responsabilidade civil ou criminal dos infratores".

\section{REFERÊNCIAS BIBLIOGRÁFICAS}

BEZERRA, M.O. A prática da corrupção no Brasil: um estudo exploratório de antropologia social. Dissertação de Mestrado. Rio de Janeiro, Museu Nacional, Antropologia Social, 1993, mimeo.

BOBBIO, N. Estado Governo Sociedade: para uma teoria geral da política. Rio de Janeiro, Paz e Terra, 1992.

BobBio, N.; MATEUCCI, N. e PASQUINO, G. Dicionário de Política. Distrito Federal, v.1,UNB/Linha Gráfica Ed., 1991

CHAUÍ, M. "Uma ideologia perversa". Folha de S.Paulo. São Paulo, Caderno Mais, 14/03/99, p.3.

COMPARATO, F.K. "Comissões Parlamentares de Inquérito: limites". Revista Trimestral de Direito Público. São Paulo, v.5, n.94, 1994.

CONGRESSO NACIONAL. Relatório Final da Comissão Parlamentar Mista de Inquérito 52/92. Edição Revisada. Brasília, Centro Gráfico do Senado Federal, agosto 1992.

DIÁRIO DO CONGRESSO NACIONAL. "Senado Federal como órgão judiciário: processo de impeachment contra o Presidente da República". Brasília, Seção II, 10/10/92.

FAORO, R. Os donos do poder. Rio de Janeiro, Ed. Globo, 1987.

FERNANDES, F. A Constituição inacabada. São Paulo. Estação Liberdade, 1989. FOUCAULT, M. Vigiar e punir. Rio de Janeiro, Vozes, 1984.

. Genealogia del Racismo. De la guerra de las razas al racismo de Estado. Madri, Ediciones La Piqueta, 1992.
HUNTINGTON, S. A ordem política nas sociedades em mudança. Rio de Janeiro/São Paulo, Ed. Forense Universitária/Edusp, 1975.

JOHNSTON, M. "O paradoxo da corrupção: efeitos grupais e sistêmicos". In: LEITE B.C. (org.). Sociologia da corrupção. Rio de Janeiro, Jorge Zahar Editor, 1987.

KLIETGAARD, R. A corrupção sob controle. Rio de Janeiro, Jorge Zahar Editor, 1994.

LIMA LOPES, J.R. de."Justiça e poder judiciário ou a virtude confronta a instituição". Dossiê Judiciário. Revista USP, n.21, mar.-maio 1994.

MARTINS, J. de S. O poder do atraso. Ensaios de Sociologia da história lenta. São Paulo, Editora Hucitec, 1994.

MÉNY, Y. "France: la fin de l'éthique républicaine?" In: DELLA PORTA; MÉNY (orgs.). Démocratie et corruption en Europe. Paris, Éd. La Decouverte, 1995.

MILLS, W.C. A elite do poder. Rio de Janeiro, Zahar Editores, 1981.

MOURÃO, G.M. Folha de S.Paulo, 29/11/83

OCAMPO, L. M. En defensa própia: cómo salir de la corrupción. Buenos Aires, Ed. Sudamericana, 1993.

OLIVEIRA, E. Crimes de corrupção. Rio de Janeiro, Forense, 1994.

OLIVEIRA, M. M. de e PASSOS, E. Comissões Parlamentares de Inquérito no Senado Federal: sua história e desempenho de 46 a 89. Brasília, Senado Federal, 1990.

QUÉRCIA, O. Entrevista. Isto É, 19/8/92.

RIOS, J.A."A fraude social da corrupção". In: LEITE, B.C. (org.). Sociologia da corrupção. Rio de Janeiro, Jorge Zahar Editor, 1987.

"Argumento e papéis da corrupção". In: OLIVEIRA, E. (org.). Criminologia crítica. Belém, Edições Cejup, 1990.

SANTOS, W.G. dos. Razões da desordem. Rio de Janeiro, Rocco, 1993.

SENADO FEDERAL. Relatório da CPI que apurou irregularidades na administração pública federal (22/88). Brasília, 1989.

SCHILling, F. Corrupção: ilegalidade intolerável? Comissões Parlamentares de Inquérito e a luta contra a corrupção no Brasil (1980-1992). São Paulo, Ed. IBCCrim, 1999.

SCHILLING, F. et alii. Violência urbana: dilemas e desafios. São Paulo, Ed. Atual, 1999.

SILVA, F.L.L. da. Para uma genealogia da corrupção. Dissertação de Mestrado. Unicamp, Instituto de Estudos da Linguagem, 1992, mimeo.

SOUSA SANTOS, B. de et alii. "Os tribunais nas sociedades contemporâneas." RBCS, n.30, 1996.

ZAFFARONI, E.R. "La corrupción; su perspectiva lationoamericana". In: OLIVEIRA, E. (org.). Criminologia crítica. Belém, Edições Cejup, 1990. 